\title{
DIVERSITAS SERANGGA TANAH DI BERBAGAI TIPE TANAH PADA LAHAN REKLAMASI BEKAS TAMBANG KAPUR KABUPATEN TUBAN
}

\author{
Dwi Oktafitria' ${ }^{1)}$, Dewi Hidayati ${ }^{2)}$, Eko Purnomo ${ }^{3)}$ \\ 1) Fakultas Matematika Dan Ilmu Pengetahuan Alam, Universitas PGRI Ronggolawe Tuban \\ $\left.{ }^{2}\right)$ Fakultas Sains, Institut Teknologi Sepuluh Nopember Surabaya \\ $\left.{ }^{3}\right)$ PT. Semen Indonesia (Persero) Tbk. \\ email: 1)dwioktafitria86@gmail.com, 2)dewi_hidayati@yahoo.co.id, \\ ${ }^{3)}$ eko.purnomo@semenindonesia.com
}

\section{Diterima 30 April 2019 disetujui 4 Mei 2019}

\begin{abstract}
The purpose of this study was to determine the diversity of soil insect orders in the reclamation area of former limestone quarries in the top soil type, spoil and reject product used in the media for land reclamation processes. This research sampling technique uses a pitfall trap tool. This study used descriptive quantitative data analysis using the Shannon-Wiener diversity index, Simpson dominance index, Pielou species evenness index, and index of Morisista-Horn habitat similarity. Based on the research that has been done it can be concluded that the reclamation land in 2010 with the dominant type of dust has a low diversity category and a high dominance category with the discovery of 4 orders. The reclaimed land in 2014 with the dominant clay type soil has a moderate diversity category and a low dominance category with 7 orders found. Whereas the reclamation land in 2016 with the dominant type of sand has a low diversity category and a high dominance category with the discovery of 8 orders. The spread of species in all three locations was categorized evenly and between locations did not have the same community.
\end{abstract}

Keywords: Insect, Soil, Diversity, Quarry, Reclamation

\section{PENDAHULUAN}

Lahan terbuka yang telah dilakukan proses penambangan memerlukan penanganan khusus untuk mengembalikannya menjadi lahan produktif. Lahan penambangan batu kapur yang cukup luas di kabupaten Tuban meninggalkan luasan yang cukup lebar. Upaya yang telah dilakukan oleh berbagai pihak adalah dengan melakukan reklamasi lahan dan melakukan penanaman tanaman jati dan lamtoro. Proses reklamasi lahan dilakukan dengan menggunakan media tanah yang berbeda-beda. Lahan reklamasi yang dilakukan pada tahun 2010 menggunakan tipe tanah reject product, lahan reklamasi yang dilakukan pada tahun 2014 menggunakan tipe tanah top soil dan lahan reklamasi yang dilakukan pada tahun 2016 menggunakan tipe tanah spoil.

Secara umum kawasan penambangan batu kapur memiliki keanekaragaman serangga tanah yang rendah karena memiliki komposisi tanah dan kondisi lingkungan yang kurang mendukung untuk kehidupan. Berbagai penelitian menyebutkan bahwa dampak negatif adanya penambangan batu kapur terhadap kondisi permukaan tanah diantaranya adalah adanya run off, berkurangnya resapan air, dan hilangnya tanah rizhosfer beserta hewan dan tanaman diatasnya (Septianella et al., 2015). Lahan yang telah direklamasi diharapkan mampu menjadi ekosistem yang stabil dengan kekayaan jenis yang melimpah. Indonesia adalah negara dengan kekayaan spesies hewan sangat tinggi dibandingkan dengan negara- 
negara lain (Septianella et al., 2015). Oleh karena itu lahan-lahan bekas tambang batu kapur dapat mendukung keberagaman spesies-spesies hewan tersebut.

Salah satu hewan penting dalam suatu komunitas terestrial khususnya lahan reklamasi bekas tambang adalah serangga tanah. Keanekaragaman serangga tanah yang tinggi mampu menyebabkan proses jaring-jaring makanan dapat berjalan dengan normal dan stabil di alam (Basna, Koneri, \& Papu, 2017). Peran serangga dalam hubungannya dengan kondisi tanah sebagai tempat hidupnya adalah serangga tanah mengubah bahan-bahan organik di tanah kemudian mengembalikannya kembali ke tanah sebagai bahan organik yang siap dgunakan oleh tanaman (Basna et al., 2017). Oleh karena itu apabila jenis tanah yang ada berbeda antara komunitas yang satu dengan yang lain maka berbeda pula keragaman serangga tanah yang ada. Serangga tanah yang memiliki jumlah individu banyak, memiliki berbagai fungsi penting serta memiliki interaksi ekologi yang kuat dengan lingkungan hidupnya, maka serangga tanah berpotensi untuk digunakan sebagai bio indikator dalam suatu ekosistem (Yuniar \& Haneda, 2015).

Penelitian mengenai keanekaragaman serangga tanah dikawasan reklamasi bekas tambang batu kapur di PT. Semen Indonesia (Persero) Tbk. masih sangat terbatas, sehingga diperlukan penelitian khususnya mengenai keanekaragaman serangga tanah tersebut. Oleh karena itu tujuan penelitian ini adalah untuk mengetahui keanekaragaman ordo serangga tanah dilahan reklamasi bekas tambang batu kapur pada tipe tanah top soil, spoil dan reject product yang digunakan dalam media proses reklamasi lahan.
Ketiga tipe tanah ini memiliki karakter yang berbeda. Topsoil adalah tanah lapisan atas yang umumnya memiliki banyak kandungan bahan organik serta subur (Sugiharyanto dan Khotimah, 2009). Tanah tipe reject adalah bahan sisa dari hasil penambangan batu kapur yang tidak memenuhi syarat untuk dijadikan bahan produksi atau kotoran buangan dari mesin pengolahan bahan baku semen yang memiliki kandungan bahan organik rendah. Tanah tipe spoil adalah tipe tanah atau batuan buangan yang tidak dibutuhkan sebagai bahan baku semen, karakteristik khas pada tanah ini adalah mudah menyebabkan terjadi erosi serta kemampuan menahan air dan nutrisi yang rendah (Jha and Singh, 1991).

\section{METODE}

Penelitian dilakukan pada lahan reklamasi bekas tambang batu kapur didalam kawasan pertambangan batu kapur PT. Semen Indonesia (Persero) Tbk, kecamatan Kerek Kabupaten Tuban (Gambar 1). Pengambilan serangga tanah dilakukan di bulan Mei-Juni 2018 pada lahan reklamasi tahun 2010 dengan tipe tanah reject product, lahan reklamasi tahun 2014 dengan tipe tanah top soil, dan lahan reklamasi tahun 2016 dengan tipe tanah spoil. Teknik sampling penelitian ini menggunakan alat pitfall trap (Agosti et al., 2000). Pitfall trap adalah alat yang berupa gelas plastik, kemudian dimasukkan kedalam lubang sehingga mulut gelas berada sejajar dengan permukaan tanah. Pitfall trap diisi dengan air sabun konsentrasi rendah untuk menahan pergerakan serangga tanah yang didapatkan (Laub, 2009). Setiap lokasi dipasang 3 plot dengan dengan setiap plot terdapat 5 pitfall trap yang memiliki jarak masing-masing 1 meter. Pitfall trap dipasang pada masing lokasi selama 2-3 hari (Agosti et al., 2000). Serangga tanah yang didapatkan 
selanjutnya dimasukkan ke dalam botol sampel yang telah diberi Alkohol $95 \%$ dan diberi label (Toda et al., 2009).

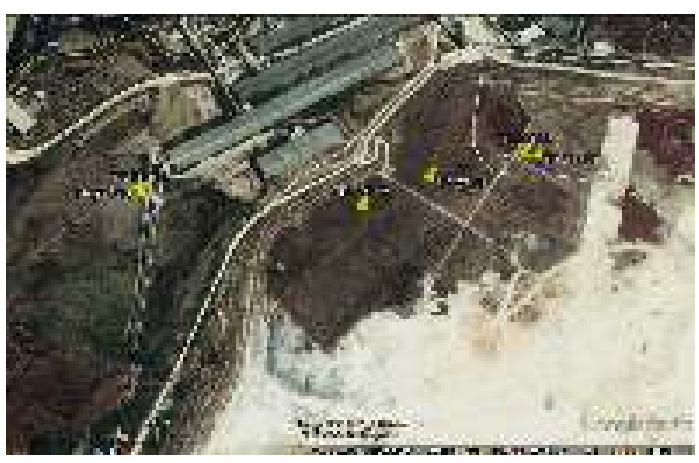

Gambar 1. Peta Lahan Reklamasi Bekas Tambang Kapur (TR 2010 A dan TR 2010 B = tipe tanah spoil; TR 2014 A dan TR 2014 B = tipe tanah top soil; TR 2016 A dan TR 2016 B = tipe tanah reject product)

Hasil pengamatan didokumentasikan kemudian dilakukan identifikasi hingga takson ordo menggunakan buku Identification Guide To The Ant Genera Of The World (Bolton, 1997), Identification Guide To Bornean Ants (Hashimoto and Rahman, 2003), An Introduction to The Study of Insects (Boror, 1992), A Synoptic Review Of The Ant Genera (Hymenoptera, Formicidae) Of The Philippines (General et al., 2012), Buku identifikasi ordo coleoptera (Amir, 2002), Ordo Hemiptera (Cassis dan Gros, 1995) dan Ordo Orthoptera (Colles dan Rentz,
1985). Penelitian ini menggunakan analisis data deskriptif kuantitatif dengan menggunakan indeks keanekaragaman Shannon-Wiener (Odum,1993), indeks dominansi Simpson (Odum, 1993), indeks kemerataan spesies Pielou (Odum, 1993), dan indeks kesamaan habitat Morisista-Horn (Magurran, 2004; Krebs, C. J., 2014).

\section{HASIL DAN PEMBAHASAN}

Berdasarkan penelitian yang telah dilakukan, diketahui bahwa terdapat 4 ordo ditemukan pada lahan reklamasi 2010 (LR 2010), 7 ordo ditemukan pada lahan reklamasi 2014 (LR 2014) dan 8 ordo ditemukan pada lahan reklamasi 2016 (LR 2016) (Tabel 1). Selain itu pada LR 2010 diketahui terdapat 202 individu dan pada LR 2014 terdapat 107 individu, sedangkan pada LR 2016 terdapat 309 individu yang tertangkap. Ordo yang ditemukan pada ketiga lahan adalah ordo Coleoptera, ordo Diptera, ordo Hymenoptera dan ordo Orthoptera. Serangga tanah yang termasuk kedalam empat ordo tersebut merupakan serangga tanah yang umum dan memiliki anggota spesies yang aktivitasnya berada di permukaan tanah (Basna et al., 2017).

Tabel 1 Ordo yang ditemukan pada penelitian

\begin{tabular}{clccc}
\hline \multirow{2}{*}{ No } & \multirow{2}{*}{ Ordo } & LR 2010 & LR 2014 & LR 2016 \\
\cline { 3 - 5 } & & \multicolumn{3}{c}{ ni } \\
\hline 1 & Coleoptera & 1 & 5 & 13 \\
2 & Collembola & - & 6 & 3 \\
3 & Diplura & - & - & 1 \\
4 & Diptera & 4 & - & - \\
5 & Hemiptera & 1 & 1 & 1 \\
6 & Homoptera & - & - & 13 \\
7 & Hymenoptera & 196 & 46 & 241 \\
8 & Isopoda & - & 45 & 30 \\
9 & Neuroptera & - & 1 & - \\
10 & Orthoptera & - & 3 & 7 \\
\multicolumn{7}{r}{} & $\sum$ & $\mathbf{2 0 2}$ & $\mathbf{1 0 7}$ & $\mathbf{3 0 9}$ \\
\hline
\end{tabular}




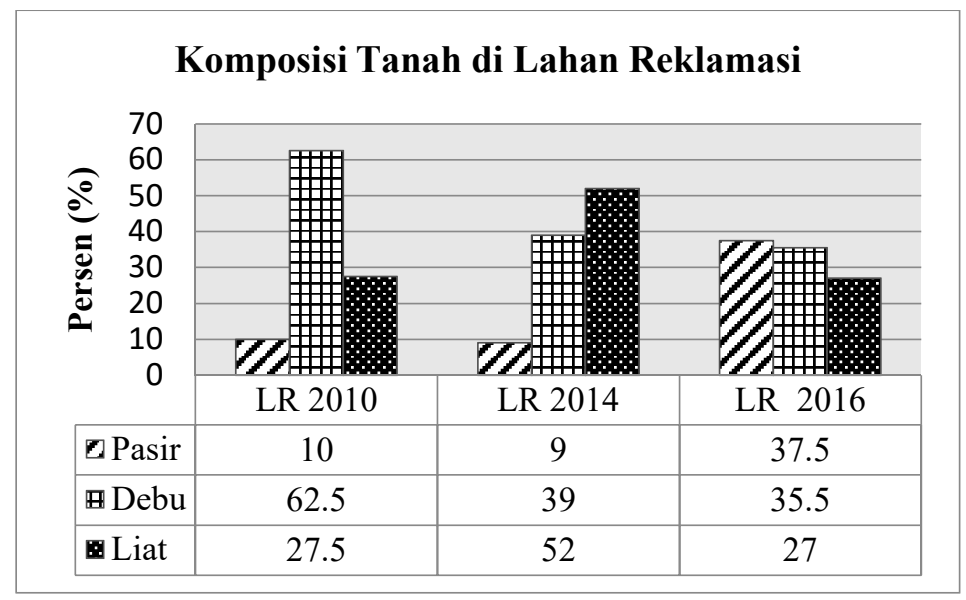

Gambar 2 Diagram komposisi tekstur tanah pada LR 2010, LR 2014 dan LR 2016

Pada perhitungan nilai indeks keanekaragaman Shannon Wiener diketahui bahwa nilai indeks keanekaragaman spesies tertinggi berturut adalah 1.22 pada LR 2014, 0.96 pada LR 2016 dan 0.16 pada LR 2010 (Gambar 3). Berdasarkan kategori nilai indeks keanekaragaman spesies, LR 2014 memiliki keanekaragaman spesies serangga tanah kategori sedang yang artinya memiliki penyebaran jumlah individu tiap spesiesnya sedang. Sedangkan berdasarkan kategori nilai indeks keanekaragaman spesies pada LR 2010 dan LR 2016, memiliki keanekaragaman spesies serangga tanah kategori rendah yang artinya memiliki tingkat penyebaran jumlah individu tiap spesiesnya rendah. Nilai indeks keanekaragaman spesies ini berbanding terbalik dengan nilai indeks dominansi.

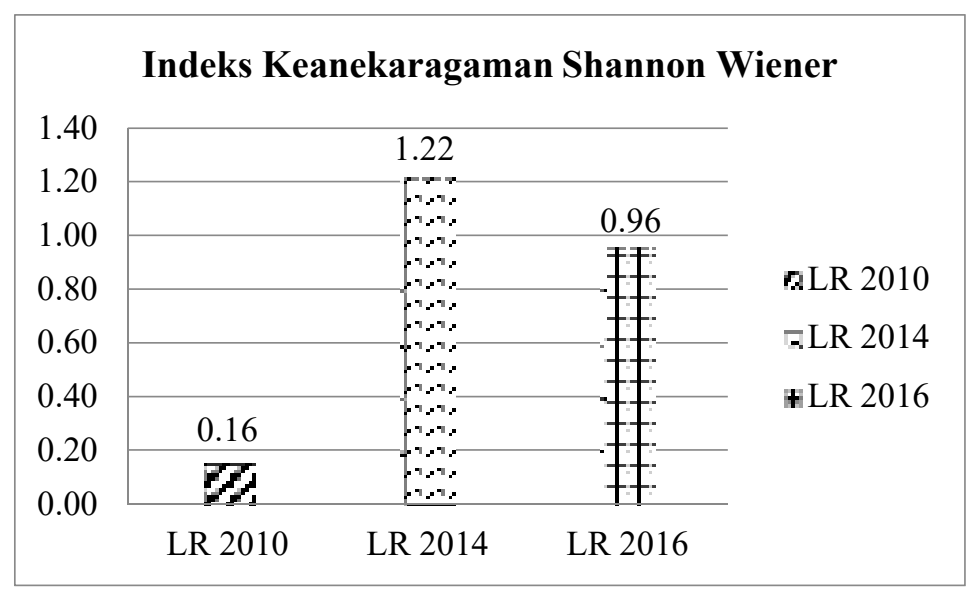

Gambar 3 Diagram indeks keanekaragaman serangga tanah pada LR 2010, LR 2014 dan LR 2016

Berdasarkan nilai indeks dominansi Simpson diketahui bahwa nilai dominansi tertinggi berturut-turut adalah
0.94 pada LR 2010, 0.62 pada LR 2014 dan 0.37 pada LR 2016 (Gambar 4). Nilai indeks dominansi pada LR 2014 
sebesar 0.37 dapat diartikan bahwa LR 2014 memiliki nillai dominansi yang rendah sehingga didalam komunitas serangga tanah pada LR 2014 tidak ada spesies yang mendominasi. Hal ini diketahui dengan adanya ordo Hymenoptera dan Isopoda yang memiliki jumlah individu hanya berselisih 1 individu. Nilai indeks dominansi LR 2010 dan LR 2016 sebesar 0.94 dan 0.62 masuk kedalam kategori $>0.5$ sehingga dapat dikategorikan memiliki dominansi tinggi yang artinya dalam komunitas tersebut memiliki spesies yang mendominasi. Pada LR 2010 spesies yang mendominasi adalah dari ordo Hymenoptera sebesar 196 individu dan pada LR 2016 spesies yang mendominasi uga dari ordo Hymenoptera sebesar 241 individu.

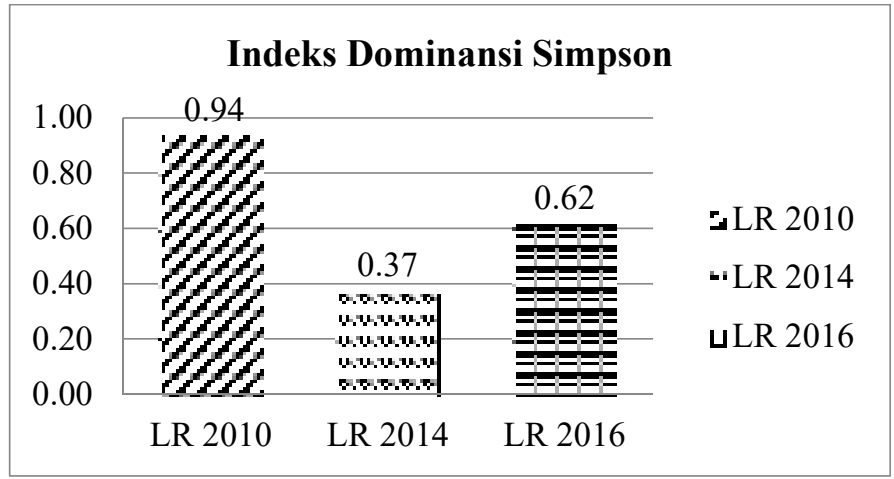

Gambar 4. Diagram indeks dominansi serangga tanah pada LR 2010, LR 2014 dan LR 2016

Nilai indeks kemerataan jenis Pielou tertinggi hingga ke rendah berturut-turut adalah 0.39 pada LR 2014, 0.30 pada LR 2010 dan 0.29 pada LR 2016 (Gambar 5). Oleh karena itu berdasarkan kategori nilai indeks kemerataan, LR 2010, LR
2014 dan LR 2016 memiliki nilai $<0.5$ yang artinya termasuk kedalam kategori mempunyai kemerataan tinggi. Hal ini berarti penyebaran jumlah individu tiap jenis spesies merata.

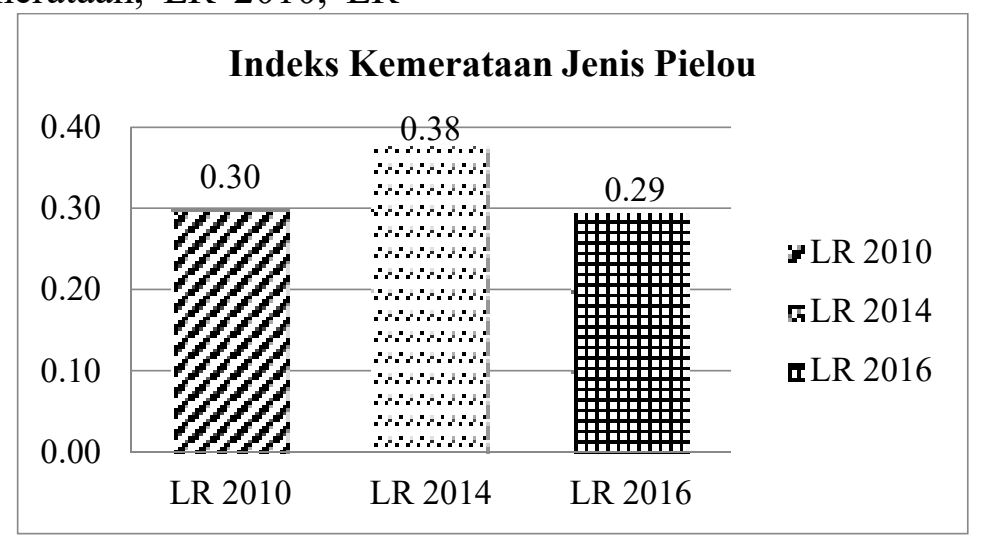

Gambar 5. Diagram indeks kemerataan serangga tanah pada LR 2010, LR 2014 dan LR 2016

Ketiga komunitas serangga tanah ditiga lokasi tersebut juga dihitung nilai indeks kesamaan komunitasnya dengan indeks Morisita-Horn. Berdasarkan nilai indeks kesamaan komunitasnya diketahui bahwa komunitas LR 2010, 
LR 2014 dan LR 2016 tidak ada kesamaan. Hal ini didasarkan kepada nilai indeks komunitas antara LR 2010 dengan LR 2014 sebesar 0.25, LR 2010 dengan LR 2016 sebesar 0.20 dan LR 2014 dengan LR 2016 sebesar 0.27. Ketiga nilai indeks kesamaan komunitas tersebut mendekati nilai 0 . Oleh karena itu berdasarkan pengelompokan kategori Krebs (2014), maka komunitas serangga tanah di LR 2010, LR 2014 dan LR 2016 tidak memiliki kesamaan. Ketidaksamaan komunitas pada masingmasing lahan reklamasi dapat dilihat dari jenis tekstur tanah dan jenis ordo yang ada didalamnya.

Ordo Hymenoptera adalah ordo yang diitemukan di semua jenis lahan reklamasi dan memiliki jumlah individu paling banyak. Salah satu anggota familia terbesar dari ordo Hymenoptera adalah yang merupakan kelompok semut (Septianella et al., 2015) (Gambar 6). Spesies semut bergerak aktif diatas permukaan tanah yang umumnya ditemukan pada serasah daun dibawah pepohonan maupun pada lubang-lubang di tanah yang menjadi sarangnya. Kelompok Hymenoptera khususnya familia Formicidae ini aktif pada siang maupun malam hari (Siriyah, 2016). Ordo Hymenoptera memiliki peran penting pula dalam pembentukan tanah yaitu dengan cara menghancurkan serasah daun dan bahan organik dengan memakannya yang kemudian mengeluarkannya kembali menjadi lingkungan (Basna et al., 2017).
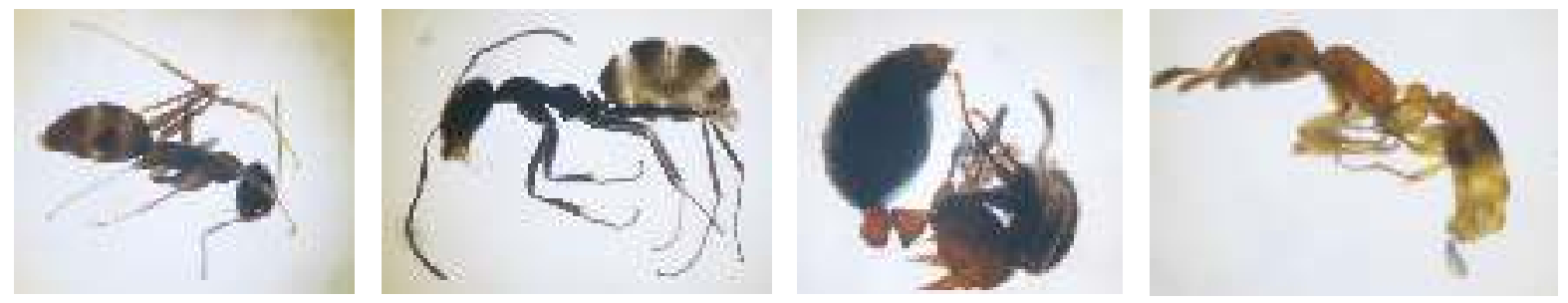

Gambar 6. Macam-macam anggota ordo Hymenoptera familia Formicidae pada LR 2010, LR 2014 dan LR 2016

Dapat dikelompokkan menjadi 3 dari peran ordo sebagai salah satu anggota serangga tanah dalam lingkungan, yaitu forager (penjelajah), predator (pemangsa) dan scavengers/ harvester (pengumpul) (Yuniar \& Haneda, 2015). Ordo Hymenoptera yang memiliki banyak anggota spesies, salah satunya Oechophylla sp. berpotensi sebagai predator hama sehingga mampu difungsikan sebagai agen pengendali hayati (Siriyah, 2016).

\section{SIMPULAN}

Berdasarkan penelitian yang telah dilakukan dapat disimpulkan bahwa lahan reklamasi tahun 2010 dengan tipe tanah dominan debu memiliki kategori keanekaragaman yang rendah dan kategori dominansi tinggi dengan ditemukannya 4 ordo. Lahan reklamasi tahun 2014 dengan tipe tanah dominan liat memiliki kategori keanekaragaman yang sedang dan kategori dominansi rendah dengan ditemukannya 7 ordo. Sedangkan lahan reklamasi tahun 2016 dengan tipe tanah dominan pasir memiliki kategori keanekaragaman yang rendah dan kategori dominansi tinggi dengan ditemukannya 8 ordo. Penyebaran spesies di ketiga lokasi dikategorikan merata dan antar lokasi tidak memiliki kesamaan komunitas. 


\section{DAFTAR PUSTAKA}

Agosti, D., J. D. Majer, L. E. Alonso and T. R. Schultz. 2000. Ants Standard Methods for Measuring and Monitoring Biodiversity. Washington and London: Smithsonian institution press.

Amir M. 2002. Kumbang Lembing Pemangsa Coccinellidae (Coccinallinae) di Indonesia. Bogor: Puslit Biologi LIPI.

Basna, M., Koneri, R., \& Papu, A. (2017). Distribusi dan Diversitas Serangga Tanah di Taman Hutan Raya Gunung Tumpa Sulawesi Utara. Jurnal MIPA Unsrat Online, 6(1), 36-42.

Bolton, B. 2007. Synopsis and Classification of The Formicidae. Memoirs of The American Entomological Institute. Vol.71: 1370

Borror, D. J., C. A.Triphelon and N. F. Johnson. 1992. An Introduction to The Study of Insects. Philadelphia: Saunders College Pub.

Cassis G, Gross GF. 1995. Zoological Catalogue of Autralia Hemiptera Heteroptera (Coleorrhyncha to Cimicomorpha). Australia: CSIRO.

Colles DH, Rentz DCF. 1985. A monograph of the Tettigoniidae of Ausralia Vol 1The Tettigoniinae. CSIRO (Commonwealth Sciencetific and Industrial Research Organization), Australia.

General, D. M. and G. D. Alpert. 2012. A Synoptic Review of The Ant Genera (Hymenoptera. Formicidae) of The Philippines. ZooKeys. 200: $1-111$

Jha, A. K. And J. S. Singh. 1991. Spoil Characteristics and Vegetation
Development of An Age Series of Mine Spoils in A Dry Tropical Environment. Vegetatio. Vol.97:63-76.

Krebs, C. J. 2014. Ecological Methodology. Vancouver: University of British Columbia.

Magurran, A. E. 2004. Ecological Diversity and Its Measurement. New Jersey: Princeton University Press.

Laub, C., R. R. Youngman, K. Love and T. Mize. 2009. Using Pitfall Trap to Monitor Insect Activity. Virginia: Virginia State University.

Odum, E. P. 1993. Dasar-Dasar Ekologi. Yogyakarta: Gadjah Mada University Press.

Septianella, G., Rosnaeni, Baskoro, Y., Nisrina, L., Qayyimah, F. D., Aulunia, R., Lupiyaningdiyah, P. (2015). Identifikasi serangga di kawasan industri pertambangan kapur Palimanan, Cirebon, Jawa Barat. In PROSSIDING SEMINAR NASIONAL MASYARAKAT BIODIVERSITAS INDONESIA (Vol. 1, pp. 1790-1794). https://doi.org/10.13057/psnmbi/m 010807

Siriyah, S. L. (2016). Keanekaragaman dan Dominansi Jenis Semut (Formicidae) di Hutan Musim Taman Nasional Baluran Jawa Timur. Biota, 1(2), 85-90. https://doi.org/10.24002/biota.v1i2 .995

Sugiharyanto dan N. Khotimah. Diktat Mata Kuliah Geografi Tanah. Yogyakarta: Univesitas Negeri Yogyakarta

Toda, M.J., Kitching, R.L. 2009. FOREST ECOSYSTEMS:the assessment of plant and animal 
biodiversity in forest ecosystems. Manual IBOY. Kyoto University Japan.

Yuniar, N., \& Haneda, N. F. (2015). Keanekaragaman semut (Hymenoptera: Formicidae) pada empat tipe ekosistem yang berbeda di Jambi. PROSSIDING SEMINAR NASIONAL MASYARAKAT BIODIVERSITAS INDONESIA, 1(7), 1582-1585. https://doi.org/10.13057/psnmbi/m 0107 